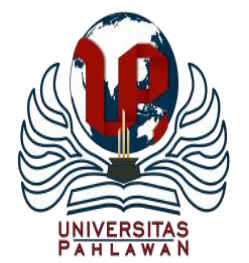

Jurnal Abdidas Volume 1 Nomor 3 Tahun 2020 Halaman 125 - 130

JURNAL ABDIDAS

Community Development Service on Educational and Health Sciences

http://abdidas.org/index.php/abdidas

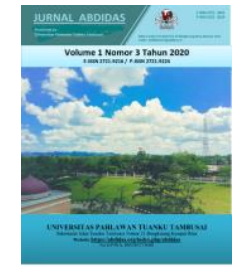

\title{
Pemanfaatan Buah Mangga Untuk Peluang Bisnis Bagi Masyarakat Desa Kalipang di Jawa Timur
}

\author{
Rasyidah Nur Aisyah ${ }^{1}$, Fitri Handayani ${ }^{2}$, Zulfa Aulia Pratiwi ${ }^{3}$, Siti Nur Kholifah ${ }^{4}$, Nuriyah Arfiyani ${ }^{5}$ \\ Universitas Pgri Wiranegara Pasuruan, Jawa Timur ${ }^{1,2,3,4,5}$ \\ E-mail: ocicyah@gmail.com ${ }^{1}$ fitri301998@gmail.com² zulfaauliapratiwi910@ gmail.com³ $^{3}$ \\ arfiyaninuriyah@gmail.com ${ }^{5}$
}

\begin{abstract}
Abstrak
Universitas PGRI Wiranegara dengan Program Tematik Berbasis Pendidikan melaksanakan program yang sudah terpilih yakni Program Kewirausahaan dalam kegiatan pengabdian masyarakat. Tujuan dari program ini untuk mencetak generasi muda di Desa Kalipang untuk berjiwa wirausaha dan bisa memanfaatkan buah mangga di sekitar rumah dengan cara mengolah menjadi asinan sehingga dapat bernilai jual lebih tinggi. Metode yang digunakan dalam kegiatan ini adalah penyampaian materi tentang olahan mangga, masalah dan solusinya, manajemen usaha dan pemasaran produk. Materi yang diberikan terdiri dari (1) pemanfaatan mangga di lingkungan rumah, (2) pengolahan asinan mangga, (3) cara pemasaran. Kegiatan ini dilakukan pada bulan Oktober sampai November 2019. Hasil dari kegiatan ini menunjukkan bahwa olahan asinan mangga memberikan nilai ekonomi bagi masyarakat di Desa Kalipang. Luaran dari kegiatan ini adalah masyarakat telah mampu melakukan pemanfaatan buah manga yang melimpah dan cara pengolahannya.
\end{abstract}

Kata kunci : wirausaha, mangga, olahan asinan mangga

\section{Abstract}

University of PGRI Wiranegara with a thematic program based have been implemented entrepreneur program in community partnership. The purpose of this program is to encourage young people in Kalipang village with an entrepreneur spirit, and can also implement the entrepreneurship program and be able to utilize the mangoes in this village and knowing the way of processing salted so that mangos can have high sales value. The method used in this activity is the delivery of material about 'processed' mango, discussion of various problems and solutions, business management and product marketing. The material provided consisted of (1) utilization of mangoes in the school environment, (2) processing of mango pickles, (3) marketing methods. This activity was carried out for 2 months. Evaluation results from this activity show that processed mango pickles have a positive impact on the school and students of MA NURUL BARI KALIPANG. The output of this activity is that students have been able to optimize the mango fruit and how to process it. Keywords: entrepreneur, mango fruit, processed mango pickles

Copyright (c) 2020 Rasyidah Nur Aisyah, Fitri Handayani, Zulfa Aulia Pratiwi, Siti Nur Kholifah, Nuriyah Arfiyani

$\triangle$ Corresponding author :

Address : Perum Pesona Candi 4 AE11 Pasuruan Jatim

ISSN 2721-9224 (Media Cetak)

Email : ocicyah@gmail.com

ISSN 2721- 9216 (Media Online)

Phone : 082143147519

DOI: https://doi.org/10.31004/abdidas.v1i3.28 


\section{PENDAHULUAN}

Kuliah Kerja Nyata (KKN) merupakan salah satu mata kuliah wajib bagi mahasiswa STKIPSTIT PGRI Pasuruan yang bersifat lapangan berupa pengabdian dilingkungan sekolah. Khususnya di tingkat MA/SMA/SMK. Madrasah Aliyah (MA) adalah jenjang pendidikan menengah pada pendidikan formal di Indonesia yang setara dengan sekolah menengah atas (SMA). Khususnya MA Nurul Badri Kalipang yang terletak di Desa Kalipang, Kecamatan Grati, Kabupaten Pasuruan.

Dalam kegiatan KKN tersebut salah satu program yang dilakukan yaitu program kewirausahaan. Kewirausahaan atau enterpreneurship pada mulanya merupakan konsep yang dikembangkan dalam tradisi sosiologi dan psikologi. Pada awal abad ke-18, Richard Cantillon, sarjana kelahiran Irlandia yang besar di Perancis, menyatakan bahwa entrepreneurship merupakan fungsi dari risk bearing. Satu abad berikutnya, Joshep Schumpeter memperkenalkan fungsi inovasi sebagai kekuatan hebat dalam entrepreneurship. Sejak saat itu, entrepreneurship merupakan akumulasi dari fungsi keberanian menanggung resiko dan inovasi (Siswoyo, 2009).

Entrepreneurship adalah suatu proses kreativitas dan inovasi yang mempunyai resiko tinggi untuk menghasilkan nilai tambah bagi produk yang bermanfaat bagi masyarakat dan mendatangkan kemakmuran bagi wirausahawan. Kewirausahaan merupakan kemampuan melihat dan menilai peluang bisnis serta kemampuan mengoptimalkan sumberdaya dan mengambil tindakan dan resiko dalam rangka mensukseskan bisnisnya.
Kewirausahaan merupakan pilihan yang tepat bagi individu yang tertantang untuk menciptakan kerja, bukan mencari kerja. Entrepreneurship adalah mereka yang berani mewujudkan ide menjadi kenyataan. Menurut Joshep Schumpeter, enterpreneurship is a person who perceives an opportunity and creates an organization to pursue it (Bygrave \& Zacharakis, 2009). Wirausaha adalah orang yang melihat adanya peluang, kemudian menciptakan sebuah organisasi untuk memanfaatkan peluang tersebut. Menurut Anoraga and Sudantoko (2002), seorang wirausaha sejati akan dinilai kemampuannya dalam hal : (1) melihat peluang, selalu berusaha memanfaatkan kesempatan baik; (2) melihat masa depan dan memiliki perencanaan yang tepat; (3) mendapatkan informasi, memanfaatkannya untuk kemajuan perusahaan; (4) mampu memimpin orang banyak. Sedangkan sikap yang harus dimiliki seorang wirausaha adalah : (1) memiliki rasa tanggungjawab; (2) selalu dinamis, ulet, dan gigih, tidak cepat menyerah karena sadar bahwa untuk mencapai kemajuan diperlukan kerja keras; (3) berani menerima kritik dan saran yang bermanfaat; (4) berinisiatif untuk maju dan melakukan yang terbaik untuk mencapai keberhasilan.

Di MA Nurul Badri Kalipang merupakan salah satu tempat yang terdapat buah mangga yang cukup melimpah. Mangga merupakan pohon yang bisa tumbuh mencapai 20 meter atau bahkan lebih. Umumnya mangga yang dibudidayakan hanya memiliki tinggi sekitar 10 meter atau kurang. Kulit batang mangga coklat kelabu sampai kehitaman. Kulit mangga bagian terluar memecah atau 
beralur. Pohon mangga bertajuk rimbun dan lebarnya bisa mencapai 10 meter (Pracaya, 2001).

Ketersediaan bahan baku buah mangga yang cukup melimpah masih kurang bisa dimanfaatkan dengan baik oleh pihak sekolah khususnya siswasiswa MA Nurul Badri Kalipang untuk dijadikan sesuatu yang cukup bernilai jual tinggi. Berdasarkan uraian diatas untuk menjadi wirausaha sejati seharusnya bisa memanfaatkan peluang yang ada dengan baik serta bersikap dinamis, ulet dan gigih.

Menurut hasil pengamatan mahasiswa KKN yaitu dapat memotivasi siswa siswa MA Nurul Badri Kalipang juga mampu bersaing dengan siswa SMK yang dicetak untuk siap kerja, maka dalam program kewirausahaan ini dilakukannya kegiatan memanfaatkan bahan baku buah mangga yang melimpah itu untuk dijadikan asinan buah mangga yang dipasarkan melalui media sosial untuk menarik minat konsumen di era modern saat ini.

\section{METODE}

Kegiatan program ini ditunjukkan pada siswa kelas X IPS MA Nurul Badri Kalipang, Kecamatan Grati Kabupaten Pasuruan, sejumlah 22 siswa. Metode yang digunakan dalam kegiatan ini adalah penyampaian materi tentang Olahan mangga, diskusi tentang berbagai masalah dan solusinya, manajemen usaha dan pemasaran produk. Materi yang diberikan terdiri dari (1) Kewirausahan, (2) Pemanfaatan mangga di lingkungan sekolah, (3) Pengolahan asinan mangga, (4) Cara pemasaran.
Kegiatan program ini terbagi dalam 3 tahap, dengan uraian sebagai berikut:

1. Tahap pertama

Tahap ini mahasiswa KKN dengan program kewirausahaan yang melaksanakan sosialisasi yang menyampaikan materi kewirausahaan, nama brand (merk), pemanfaatan mangga di lingkungan sekolah .

Kegiatan pembelajaran ini dikemas dalam metode pembelajaran Forum Grup Diskusi (FGD) berupa tanya jawab antara siswa dan mahasiswa KKN agar siswa juga mampu mengembangkan kecakapan sosialnya. Seluruh kegiatan ini juga melibatkan mahasiswa Kuliah Kerja Nyata Universitas PGRI Wiranegara Pasuruan, Siswa dan pihak sekolah MA Nurul Badri Kalipang. Mahasiswa juga menjelaskan mengenai Perlu adanya brand agar dapat menarik konsumen sehingga dapat mempercantik kemasan produk.

Nama brand yang digunakan yaitu "ASINAN KETAR-KETIR", filosofi nama brand tersebut yaitu berawal dari timbulnya rasa takut (ketar-ketir) mahasiswa KKN jika melintasi daerah perbatasan kampung begal. Selanjutnya siswa juga diwajibkan untuk memposting pamflet asinan yang sudah disediakan oleh mahasiswa KKN. Agar nantinya siswa sebelum praktek membuat olahan asinan sudah ada orderan dari konsumen melalui pemasaran secara online. 


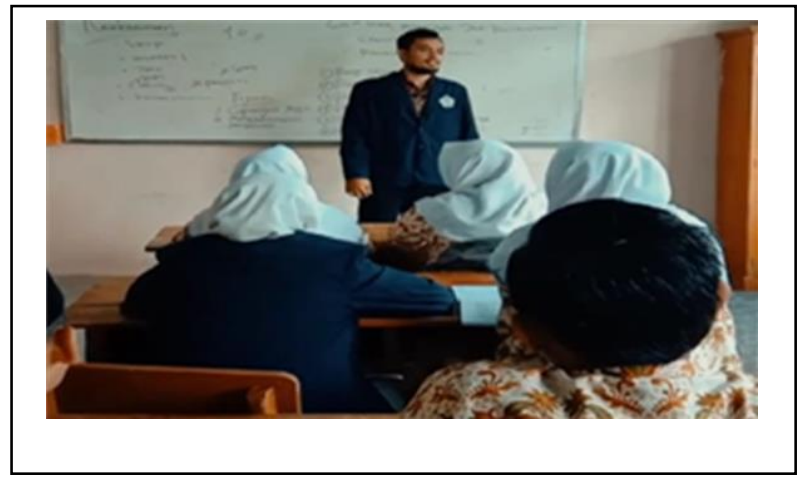

Gambar 1. Kegiatan sosialisasi Kewirausahaan tahap pertama

2. Tahap kedua

Pada tahap kedua siswa diminta untuk membawa perlengkapan untuk praktek pembuatan asinan buah mangga. Perlengkapan yang harus dibawa oleh siswa meliputi: sendok, piring, pisau, baskom, dll. Olahan buah mangga berupa pembuatan asinan. Pada kegiatan ini juga disampaikan tentang proses pembuatan mulai dari awal sampai akhir. Mereka juga langsung praktek per kelompok, 1 kelompok terdiri dari 7 (tujuh) siswa. Mereka juga diberi kesempatan satu per satu untuk mengolah asinan mangga. Setelah olahan asinan. Pada hari itu juga siswa tidak hanya praktek melainkan membuat orderan lima puluh (50) cup asinan ketar ketir hasil dari pemasaran secara online. Harga per cupnya lima ribu rupiah.

3. Tahap ketiga

Pada tahap terakhir mahasiswa beserta siswa MA Nurul Badri menghitung hasil yang diperoleh. Mulai dari berapa modal yang dikeluarkan sampai berapa keuntungan yang didapatkan.

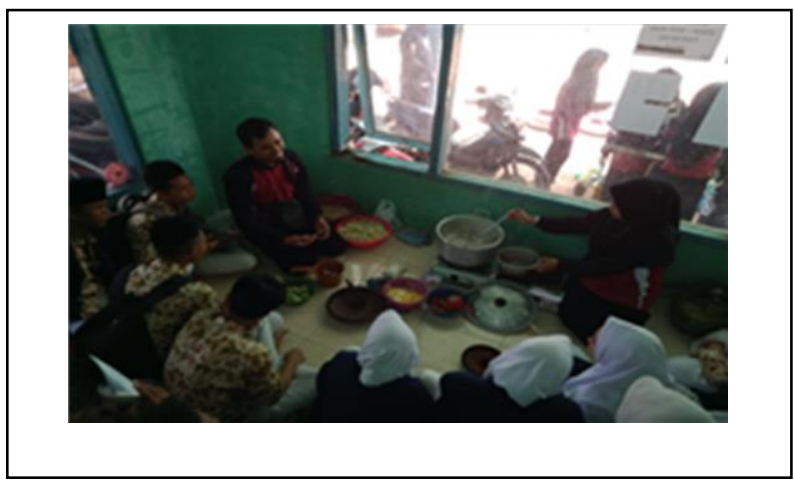

Gambar 2. Kegiatan pelatihan pembuatan asinan buah mangga

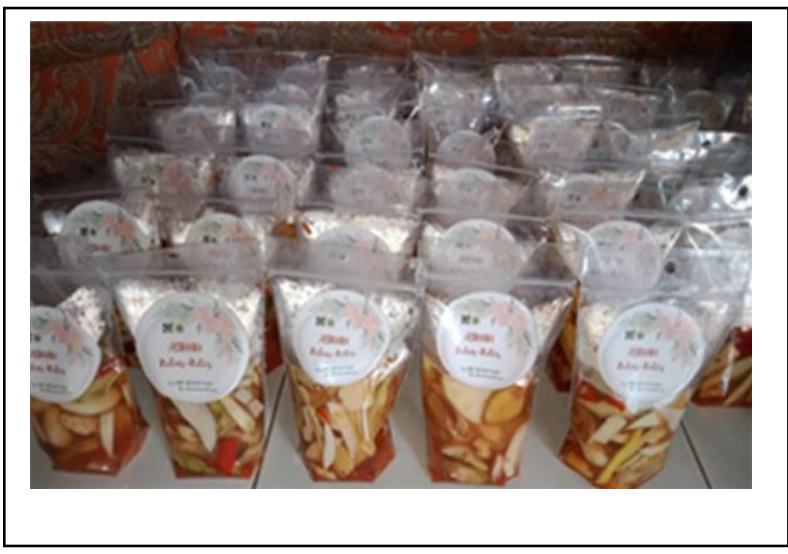

Gambar 3. Hasil produksi pelatihan pembuatan asinan buah mangga

\section{HASIL DAN PEMBAHASAN}

Program ini dilaksanakan di MA Nurul Badri kelas X IPS di Desa Kalipang Kecamatan Grati Kabupaten Pasuruan. Desa Kalipang termasuk salah satu Desa yang menghasilkan buah mangga yang cukup melimpah. Khususnya di MA Nurul Badri Kalipang terdapat banyaknya buah mangga yang masih kurang dimanfaatkan sehingga munculnya inisiatif untuk menjalankan program kewirausahaan dalam memanfaatkan buah mangga yang lebih bernilai jual tinggi.

Dengan adanya program kewirausahaan ini terdapat banyak manfaat kepada siswa-siswi yang 
awalnya tidak bisa memanfaatkan peluang akhirnya muncul antusias untuk berwirausaha. Selanjutnya harapan mahasiswa kkn terhadap siswa-siswa MA Nurul Badri dapat mengimplementasikan hasil yang diperoleh baik kesekolah maupun masyarakat.

Setelah memberikan materi kewirausahaan siswa dapat menerapkan apa yang sudah di arahkan. Dengan memanfaatkan buah yang ada di sekitar sekolah dengan membuat peluang baru agar dapat mempunyai jiwa wirausaha. Dengan itu setelah diadakannya sosialisasi, dapat memberikan kesempatan untuk siswa-siswi praktek membuat asinan yang memanfaatkan buah mangga disekitar sekolah.

Dengan diberikannya modal sebesar Rp. 100.000,- dapat digunakan untuk membeli perlengkapan asinan. Mulai dari membeli standing pouch dan bahan-bahan asinan buah mangga. Harga produk yang dipasarkan sebesar Rp. 5.000/cup. Cara pemasaran nya memanfaatkan media sosial, sehingga dengan mudah menarik minat konsumen. Keuntungan yang didapat dari hasil penjualan asinan tersebut adalah sebesar Rp. 250.000,- sehingga dapat memberikan kepuasan bagi program yang dijalankan. Output yang di peroleh siswa-siswi MA Nurul Badri diharapkan dapat mengimplementasikan hasil yang diperoleh setelah pelatihan kewirausahaan.

Setelah melakukan sosialisasi dan pelatihan, program kewirausahaan melakukan evaluasi dengan memberikan kuisioner. Berdasarkan hasil survei pada akhir kegiatan, sebanyak $75 \%$ siswa menyatakan setuju dengan adanya program pelatihan kewirausahaan.
Respon siswa terhadap kegiatan pelatihan kewirausahaan terlihat sangat menyenangkan terlihat pada gambar sebagai berikut :

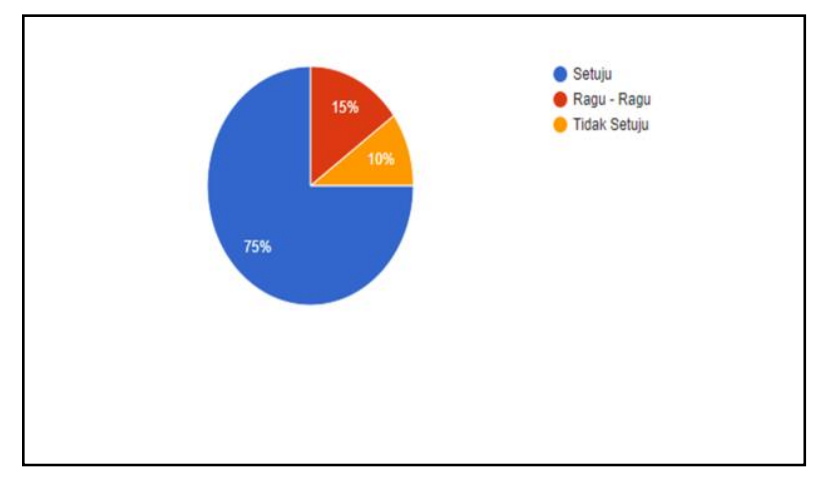

Gambar 4. Respon siswa terhadap pernyataan bahwa program kewirausahaan sangat bermanfaat.

\section{SIMPULAN}

Kewirausahaan merupakan pilihan yang tepat bagi individu yang tertantang untuk menciptakan kerja, bukan mencari kerja. Siswasiswi MA Nurul Badri Desa Kalipang Kecamatan Grati memiliki respon yang sangat positif terhadap kegiatan pengabdian masyarakat yang berbasis pendidikan program kewirausahaan yang memanfaatkan buah mangga disekitar sekolah. Hal ini dapat dilihat dari semua kegiatan yang telah dilakukan, siswa-siswinya sangat tertarik dan berperan aktif dalam kegiatan program kewirausahaan yang memanfaatkan buah mangga. Dapat dilihat dari data kuisioner bahwa sebanya $75 \%$ siswa setuju dengan adanya program kewirausahaan.

\section{DAFTAR PUSTAKA}

Anoraga, P., \& Sudantoko, D. (2002). Koperasi, Kewirausahaan dan Usaha Kecil. In Rineke Cipta.

Bygrave, W. D., \& Zacharakis, A. (2009). The 
130 Pemanfaatan Buah Mangga Untuk Peluang Bisnis Bagi Masyarakat Desa Kalipang di Jawa Timur Rasyidah Nur Aisyah, Fitri Handayani, Zulfa Aulia Pratiwi, Siti Nur Kholifah, Nuriyah Arfiyani DOI: https://doi.org/10.31004/abdidas.v1i3.28

portable MBA in Entrepreneurship. In John Willey \& Sons, Inc (Vol. 4, Issue 1). https://doi.org/10.1017/CBO9781107415324. 004

Pracaya. (2001). Bertanam Mangga (Issue 1). Penebar Swadaya.

Siswoyo, B. B. (2009). Pengembangan Jiwa Kewirausahaan di Kalangan Dosen dan Mahasiswa. Jurnal Ekonomi Bisnis, 2, 114122. BB Siswoyo - Jurnal Ekonomi Bisnis, 2009 - fe.um.ac.id 